\title{
PROVISION OF LOW VISION SERVICE IN THE DEPARTMENT OF OPHTHALMOLOGY UNIVERSITY OF CALABAR TEACHING HOSPITAL
}

BY

\author{
* EKPENYONG, B. N. AND NDUKWE, O. C. \\ DEPARTMENT OF OPHTHALMOLOGY, \\ UNIVERSITY OF CALABAR, CROSS RIVER STATE NIGERIA \\ Email: benyita2001@yahoo.com \\ * Corresponding author
}

\begin{abstract}
A low vision service is a variety of services being offered to visually impaired persons. This includes the assessment of residual vision and needs, and the identification of ways and means to address the problem. This paper describes the provision of low vision services in the Department of Ophthalmology, University of Calabar Teaching Hospital (UCTH). The clinical records of low vision patients seen at the Low Vision unit of the eye clinic from January 2008 to December 2009 were reviewed. A total of seventy four (74) low vision patients were assessed over the said period. About $75.68 \%$ of the low vision patients were male. Approximately 50\% were 50 years and above and the causes of low vision were glaucoma $(33.33 \%)$, corrected and uncorrected cataract (14.67\%), retinal dystrophies (13.33\%) and maculopathy (8.0\%). The most common visual acuity range after low vision assessment was $<6 / 18 \quad 6 / 60(58.57 \%)$, but only $30.40 \%$ of the prescribed low vision devices were dispensed. The basic challenges faced include poor acceptance of the use of devices due to cosmetic reasons, durability and cost, lack of adequate referral and ignorance.
\end{abstract}

KEYWORDS: Low vision services, Residual vision, Low vision assessment, Retinal dystrophies

\section{INTRODUCTION}

Low Vision has many definitions, it is often referred to as visual impairment, visual disability or partial sight, but in general it is any loss of functional vision that persists after the correction of distance refractive error and common eye related or surgical presbyopia. It is however argued that visual impairment refers to a loss of organ function as defined by objective criteria such as reduced visual acuity or restricted visual field. Low vision on the other hand, refers to an inability to perform everyday tasks, such as reading or recognizing faces, resulting from a visual impairment. Low vision is a disability as opposed to impairment. It can also be said to be a consequence of visual impairment ${ }^{2}$. Low vision may also be defined objectively by task performance or subjectively by self reported task difficulty $^{2}$.

World Health Organisation (WHO) has definitions which are used for surveys, and for service provision in low vision. The definitions use visual acuity and a measurement of visual field. The WHO definition of low vision for surveys is a visual acuity of less than $6 / 18$, but equal to or less than $3 / 60$, or a corresponding visual field loss in the better eye with best possible correction. Low vision as defined by $\mathrm{WHO}^{3}$ Bangkok definition for low vision services and care is as follows:

"A person with low vision is one who has impairment of visual functioning even after treatment and/or standard refractive correction, and has a visual acuity of less than $6 / 18$ to light perception, on the better eye or a visual field less than 10 degrees from the point of fixation, but who uses, or is potentially able to use, vision for the planning and/or execution of a task for which vision is essential".

Based on all these definitions, estimates of the prevalence of low vision vary widely according to the definition of the disability and methods of assessment used.

According to a release by $\mathrm{WHO}^{4}$ there are 314 million visually impaired people in the world today, 37million are blind, 124 million are low vision after best correction, and 153 million people world wide are visually impaired due to uncorrected distance refractive error causing 
problem with distance vision. It is therefore estimated that about 65 million persons with visual impairment are 'true' low vision that will require low vision care. In addition to the 153 million people with vision loss due to distance refractive error, there are hundreds of millions who have severe near vision impairment (near vision equivalent to $<6 / 18$ in the better eye) due to uncorrected presbyopia. This figure is an under estimation and is expected to double by the year 2020, due to the rapid growth of the elderly population.

In Nigeria, according to the recent National blindness and visual impairment population based survey published in 2009, there is over 1 million Nigerian adults with blindness and 4.25 million with low vision ${ }^{5,6}$.

According to Mohammed et al ${ }^{6}$, the major causes of Low vision in Nigeria as released in the Nigeria National blindness and visual impairment survey are, cataract, glaucoma, and uncorrected refractive error, and that $84 \%$ of all causes of blindness were either preventable or treatable. This is comparable to other reports from Nigeria ${ }^{7-9}$ and other countries in Africa such as Ghana ${ }^{10}$ and Cameroon ${ }^{11}$. Globally, the causes of visual impairment have been given as cataract $47.8 \%$, glaucoma $12.3 \%$, age related macular degenerarion $8.7 \%$, corneal opacities $5.1 \%$, diabetic retinopathy $4.8 \%$, childhood blindness $3.9 \%$, trachoma $3.6 \%$, and onchocerciasis $0.8 \%{ }^{12}$

According to Pararajasegaram ${ }^{13}$, the coverage of low vision care and the uptake of services where available have remained low even in most industrialized countries, while the coverage is almost negligible in low income countries. This is partly due to lack of awareness about the importance of low vision services among professional groups involved in the delivery of eye care and the community.

Blindness and Low Vision are major causes of morbidity and have profound effects on the quality of life of many people. They inhibit mobility and economic well-being of individuals affected as well as their families. Most of those with low vision are older people, but whilst the number of children is small, the burden in life years with low vision is significant.

The burden of low vision is huge, and therefore data on provision of low vision services has become necessary for planning of low vision care and to provide quality care to people with low vision so that they can realize as much visual function as possible and enjoy the same quality of life as those with normal eye sight.

\section{RESEARCH METHODOLOGY}

The WHO working definition of low vision (best corrected visual acuity of $<6 / 18$ to light perception on the better eye) was used in this study. All patients were seen by the Ophthalmologist and Optometrist before referral to the low vision unit. Only patients with severe functional visual ability in spite of loss are referred for low vision assessment.

Data were extracted from the clinical records of all low vision patients referred to the low vision unit of the Department of Ophthalmology, UCTH between January 2008 and December 2009. The information extracted included age, sex, sociodemographic details, diagnosis, presenting and best corrected visual acuities (VA) for near and distance, the spectacles and optical low vision devices prescribed.

Data were analyzed using simple proportion and percentages

\section{RESULTS}

A total of 74 clinical case notes of low vision patients seen at the low vision unit of the Department of Ophthalmology, UCTH from January 2008 to December 2009 were reviewed, $75.68 \%$ of them were male while $24.32 \%$ were females as shown in table 1 . The age range of the patients was from 4years to 92years, with a mean age of 47.60 \pm 7.70 years. Most cases of low vision patients were found in the 50 and above age group $(48.65 \%)$ as shown in table 2 .

Tables 3 and 4 show that the visual acuity of $89.55 \%$ and $90.91 \%$ of the low vision patients seen improved to $>6 / 18$ to $6 / 60$ at far and to $0-1.5 \mathrm{M}$ at near (respectively), while about $10 \%$ will require low vision rehabilitation.

The main causes of low vision as seen in this study were glaucoma $(33.33 \%)$, cataract/ 
pseudophakia (14.67\%), retinitis pigmentosa $(9.33 \%)$, maculopathy/ macular degeneration $(8.00 \%$,$) albinism (8.00 \%)$, high refractive error $(8.00 \%)$, optic atrophy $(5.33 \%)$, amblyopia $(4.00 \%)$, retinal degeneration $(4.00 \%)$, toxoplamosis $(2.67 \%)$ and others which include corneal degeneration and optic neuritis constituted (2.67\%), as shown in table 5 .

The relationship between prescribed and dispensed low vision devices is shown in table 6. The result showed that spectacle magnifiers $(49.60 \%)$ were the most prescribed low vision device, followed by telescope (32.80\%), handheld magnifiers $(9.60 \%)$ and stand-magnifiers $(8.00 \%)$. Only $30.40 \%$ of prescribed low vision devices were dispensed, out of which spectacle magnifiers constituted $19.20 \%$, telescope $4.80 \%$, stand magnifiers $4.00 \%$ and handheld magnifiers $2.40 \%$.

\section{Table 1:}

\section{Sex distribution of low vision patients seen}

\begin{tabular}{lll}
\hline Sex & No. of low vision patients seen $\quad \%$
\end{tabular}

\begin{tabular}{lll}
\hline Male & 56 & 75.68
\end{tabular}

Female

18

24.32

Total

74

100.00

Table 2: Distribution of low vision patients seen by age and sex

\begin{tabular}{|c|c|c|c|}
\hline$\overline{\text { Age }}$ & Male & Female & Total $(\%)$ \\
\hline$\overline{0-9}$ & 6 & 2 & $8(10.81)$ \\
\hline $10-19$ & 3 & 1 & $4(5.41)$ \\
\hline $20-29$ & 9 & 2 & $11(14.86)$ \\
\hline 30-39 & 8 & 1 & $9(12.16)$ \\
\hline $40-49$ & 2 & 4 & $6(8.11)$ \\
\hline $50-59$ & 7 & 2 & $9(12.16)$ \\
\hline $60+$ & 21 & 6 & 27 (36.49) \\
\hline$\overline{\text { Total }}$ & $56(75.68 \%)$ & $18(24.32 \%)$ & $74(100)$ \\
\hline
\end{tabular}

\section{DISCUSSION}

It is generally recognized that the problem of low vision is significant and that it is increasing rapidly, particularly in the context of the 'greying'
Table 3: Comparison of Distance Visual Acuity grading at presentation and after correction

Distance visual acuity At presentation (\%) After correction (\%)

\begin{tabular}{lrr}
\hline$>6 / 18-6 / 60$ & $41(58)$ & $60(89.55)$ \\
$<6 / 60-3 / 60$ & $25(35.71)$ & $5(7.46)$ \\
$<3 / 60-\mathrm{PL}$ & $4(5.72)$ & $2(2.99)$ \\
\hline Total & $\mathbf{7 0 ( 1 0 0 )}$ & $\mathbf{6 7}(\mathbf{1 0 0})$
\end{tabular}

of populations ${ }^{13}$. This is in accordance with the result of this study which has shown that almost half the population of low vision patients seen is 50years and above.

The results of this study showed that the males (75.68\%) were mostly affected by low vision. Barbie $^{9}$ in reporting the characteristics of the Nigerian low vision population in Evengelical Church of West Africa (ECWA) eye hospital found that $70.3 \%$ of the study population was male. This could be because the male seem to have more economic power and as the heads and bread winners of family, they go extra mile seeking to improve their vision and leave up to their responsibility.

The most important cause of low vision in this study was glaucoma (33.33\%), followed by pseduoaphakia/ cataract $(14.67 \%)$, retinal dystrophies (albinism, $8.00 \%$ and retinitis pigmentosa, 9.33\%) and maculopathy (8.00\%). This result is similar to the finding in ECWA eye hospital Kano'. Glaucoma is therefore increasing in importance in Nigeria and some other developing countries as a major cause of low vision.

On the contrary, epidemiological studies carried out in some developed countries, have shown that the pattern of causes of low vision is different, where approximately half of low vision referrals are for patients with age-related macular degeneration. Other eye diseases such as Glaucoma, Diabetic retinopathy, Optic Neuropathies, Retinitis Pigmentosa, and Cataract each account for $10 \%$ or fewer referrals ${ }^{14-16}$.

The highest percentage of prescribed low vision devices were spectacle magnifiers $(49.60 \%)$ 
Table 4: Comparison of near visual acuity grading at presentation and after correction

\begin{tabular}{lrr}
\hline Near acuity & No. presentation (\%) & No. Corrected (\%) \\
\hline Normal up to 1.5M & $21(30.0)$ & $60(90.91)$ \\
$>1.5 \mathrm{M}-2.5 \mathrm{M}$ & $17(24.29)$ & $2(3.03)$ \\
Very large $>2.5 \mathrm{M}$ & $32(45.71)$ & $4(6.06)$ \\
\hline Total & $\mathbf{7 0 ( 1 0 0 )}$ & $\mathbf{6 6}(\mathbf{1 0 0})$ \\
\hline
\end{tabular}

because of their high durability, availability and acceptability by the patients, followed by telescopes, stand and handheld magnifiers. Similar studies have also shown that spectacle magnifiers are the commonest prescribed and acceptable low vision device ${ }^{17,18}$. On the contrary, the hand

Table 5: Causes of low vision as seen in UCTH

\begin{tabular}{lr}
\hline Eye Disease & No. of Patients (\%) \\
\hline Albinism & $6(8.00)$ \\
Amblyopia & $3(4.00)$ \\
Cataract (corrected/uncorrected) & $11(14.67)$ \\
Glaucoma & $25(33.33)$ \\
High refractive error & $6(8.00)$ \\
Maculopathy/Macular degeneration & $3(4.00)$ \\
Optic atrophy & $4(5.33)$ \\
Retinal degeneration & $3(4.00)$ \\
Retinitis pigmentosa & $7(9.33)$ \\
Toxoplasmosis & $2(2.67)$ \\
Others & $2(2.67)$ \\
\hline
\end{tabular}

Total

$75 *(100)$

* Note: The total number of cases enumerated in table 5 was 75 as against 74 clinical records studied because in a particular clinical record, the patient had both glaucoma and cataract. magnifier was the most prescribed low vision aid for near $(38.8 \%)$ in Brazil ${ }^{19}$. However only about $30.40 \%$ of prescribed low vision devices were dispensed, this could be due to cost, acceptability and ignorance.

The data of this study showed that about $10 \%$ of the low vision patients seen at the UCTH, Calabar could benefit from low vision rehabilitation. However, it is gratifying to note that about $90 \%$ of low vision patients seen showed improvement with distance and/or near visual acuity with the help of spectacles, magnifiers (stand, handheld, and telescope) or both. Studies carried out in India $^{20}$ and West Africa ${ }^{21}$ indicate that more than half of low vision patients show an improvement in vision loss with low vision devices after low vision assessment. Low vision aids are therefore an effective means of providing visual rehabilitation, helping greater percentage of patients with visual disability.

Low Vision is one of the challenges faced by the World generally and developing countries in particular. The findings of this study have further shown that the education, employment prospects, independence and quality of life of people with low vision could be improved by enhancing vision, through provision of quality and affordable low vision services.

Table 6: Relationship between optical devices prescribed and dispensed

\begin{tabular}{lll}
\hline Type of device & No. prescribed (\%) & No. prescribed (\%)
\end{tabular}

\begin{tabular}{lll}
\hline Spectacle magnifier & $62(49.60)$ & $24(19.20)$
\end{tabular}

Telescope

$41(32.80)$

$6(4.80)$

Stand magnifier/dome

$10(8.00)$

$5(4.00)$

Handheld

$12(9.60)$

$3(2.40)$

\begin{tabular}{lll}
\hline Total & $125(100)$ & $38(30.40)$
\end{tabular}




\section{REF E R E N C E S}

1. Barbara, B. (1997): The low vision hand book. Slack incorporated, USA, pp1-5.

2. Johnson, G. J., and Foster, A. (2003): Prevalence, incidence and distribution of visual impairment. In: Johnson GJ, Minassian DC, Weale RA and Sheila KW edns. The epidemiology of eye disease. 2nd Edn. A Hodder Arnold Publication, pp.13-28.

3. World Health Organization (1997): Global initiative for the elimination of avoidable blindness. Geneva, World Health Organization, WHO/PBL/97.61 Rev.1.

4. WHO press release (2006): Sight test and glasses could dramatically improve the lives of 150 million people with poor vision. Geneva. September 11.

5. Kyrai, F., Murthy, G. V. S. and Sivasubramaniam, S. (2009): Prevalence of blindness and visual impairment in Nigeria. The Nigeria National blindness and visual impairment survey. Invest, Ophthalmol. Vis. Sci, 50: 2033-9.

6. Abdull, M. M., Sivasubramaniam, S., Gudlavalleti, V. S. M., Gilbert, C., Abubakar, T., Ezelum, C. and Rabiu, M. M. (2009): Causes of blindness and visual impairment in Nigeria: The Nigeria National blindness and visual impairment survey. Invest. Ophthalmol. Vis. Sci, 50; 4114-20.

7. Abiose, A., Murdoch, I. and Babalola, O. (1994): Distribution and aetiology of blindness and visual impairment in mesoendemic Onchoceral Communities, Kaduna State Nigeria Br. J. Ophathalmol, 78:8-13.

8. Abdul, L. (2002): Prevalence and causes of blindness and Low Vision in Dambatta Local Government Area, Kano State, Nigeria. Nig. J. Med, 11:108-12.

9. Barbie, M. E, (2004): Characteristics of the Nigeria low vision population. JNOA, 11: 6-
10.

10. Ovenseri-Ogbomo, G. O. and Morny, E. K. (2008): Causes of visual impairment in Central Region of Ghana. JNOA, 14: 11-3.

11. Wilson, M. R., Mansour, M., Ross-Degnan, D., Moukouri, E., Fobi, G., Alemayehu, W., Martone, J. F., Casey, R. and Bazargan, M. (1996): Prevalence and causes of low vision and blindness in the extreme North Province of Cameroon, West Africa. Ophthalmic Epidemol, 3(1): 23-33.

12. Resnikoff, S., Pascolini, D., Etya'ale, D., Kocur, I., Pararajasegaram, R., Pokharel, G. P. and Mariotti, S. P. (2004): Global data on visual impairment in the year 2002. Bull. WHO, 82:844-95.

13. Pararajasegaram, R. (2004): Low vision care; the need to maximize visual potential. J. Comm. Eye Hlth, 17(49):1-2.

14. Munoz, B., West, S. K., Rubin, G. S., Schein, O. D., Quigley, H. A., Bressler, S. B. and Bandeen-Roche, K. (2000): Causes of blindness and Visual impairment in a population of older American: The Salisbury Eye Evaluation Study. Arch. Ophthalmol, 118:819-25.

15. Leat, S. J., and Rumney, N. J. (1990): The experience of a University-based low vision clinic. Ophthalmol. Physiol. Opt, 10:8-15.

16. Elliot, D. B., Trukolo-Ilic, M., Strong, J. G., Pace, R., Plotkin, A. and Bevers, P. (1997): Demographic characteristics of the visiondisabled elderly. Invest. Ophthalmol. Vis. Sci, 38:2566-75.

17. Paudel, P., Khadka, J. and Sharma, A. K. (2005): Profile of a low vision population. International congress series (1282); 252-6.

18. Hassan, M. and Iman, A. H. (2004): Low vision devices and training. J. Comm. Eye Hlth, 17(49): 6-9. 
19. Haddad, M. A., Sampaio, M. W., Temporini, E. R. and Kara-José, N. (2002): Low vision in the elderly at a University hospital in Brazil. Abstracts for vision 2002 International Society for Low Vision Research and Rehabilitation, p.126.
20. Peter, H. and Vijaya, K. G. (2003): Survey of visual impairment in an Indian tertiary eye hospital. J. Comm. Eye Hlth, 16(45):14

21. Ager, L. R. (1988): Optical Services for visually impaired children. J. Comm. Eye Hlth, 11(27): 38-40. 